\title{
Response to Schroeter-Kunhardt
}

To the Editor:

Thank you for the opportunity to reply to Michael SchroeterKunhardt's critique of our research. His comments combine wrong assertions about our study with misunderstanding of our methodology. This may sound harsh, so let me shortly refute his arguments.

As we mentioned in our article in this Journal (Knoblauch, Schmied, and Schnettler, 2001) as well as widely in our German publications, we have conducted two waves of interviews, each with more than 2,000 subjects. Schroeter-Kunhardt seemed unaware of the fact that we dealt with many more subjects than those in the first wave. As we also stress explicitly (in fact, we have written an essay on this in the edited volume Schroeter-Kunhardt cited), we have collected a large number of qualitative interviews, so that the number of cases amounts to more than 200.

Methodologically, these cases cannot be lumped together. Qualitative and quantitative interviews have to be distinguished, and the second wave cannot be added to the first one. Instead, it constitutes a confirmatory test of the first wave-and, as we mentioned, a surprisingly convincing test that corroborated the first wave's results. 
The question as to the "death" of the patients is essentially not subject to interpretation. The questionnaire, which was printed in our edited book (Knoblauch and Soeffner, 1999), as well as in my monograph (Knoblauch, 1999), included two clear-cut yes/no answers as to both the subjective and the medical evidence of the subjects' physical situation. Any additional "medical" information on the situation by the subjects was, as we noted, qualitatively too diverse and too unreliable to be interpreted on its own. It is these answers, which include items such as "had an accident" or "injured," that Schroeter-Kunhardt seems to be "interpreting."

Nowhere in our book did we claim, or intend to claim, that "physical crises were not related to organic fact." I suspect that SchroeterKunhardt was confusing that with "psychical crises."

Schroeter-Kunhardt was wrong in his assertion that we did not know if our subjects had knowledge about NDEs before their own NDE. In fact, this was a question in the questionnaire, and the answer was stated in the very essay he cited (Schmied, Knoblauch, and Schnettler 1999, p. 232).

Schmidt-Degenhard's notion of oneiroids is interesting, but it did not seem useful to us. However, if one does use it, one should be aware that Schmidt-Degenhard took NDEs to be one type of oneiroid, so that the distinction between NDEs and oneiroids, as Schroeter-Kunhardt suggested, does not work logically.

Schroeter-Kunhardt referred to his own research on NDEs, but he has not, to our knowledge, published anything about his empirical work. As to the differences between East and West German NDEs, we stated the statistical significance explicitly (Schmied, Knoblauch, and Schnettler, 1999 , p. 234), and indicated that most differences were tendencies.

The cultural interpretation of these differences is, in fact, subject to further discussion, and we offered our interpretation as part of our discussion. Yet, Schroeter-Kunhardt's claim that I said anywhere that in China there existed no out-of body-experiences is plainly false. In my book (Knoblauch, 1999) I wrote that one finds in China "motifs like out-of-body experiences, tunnel, etc." (p. 86), and in the corresponding footnote, I did refer to Feng Zhi-ying and Liu Jian-xun's study (p. 214).

Schroeter-Kunhardt argued that the fact that some NDEs consist only of single elements does not contradict the universality of NDEs. The point is not that NDEs may consist of one single element, but that these elements may differ from anything mentioned in the standard experience as described, for example, by Raymond Moody. 
We did not "reduce the NDE to a social narrative," as SchroeterKunhardt asserted. To the contrary, as one may see in the conclusion of our book (Knoblauch and Soeffner 1999), we tried to offer an anthropological explanation that integrates "culturalist" and biological approaches.

Finally, Schroeter-Kunhardt seemed unaware of the "consequential" dimension in the psychology of religious experience. In this respect, one typically distinguishes changes in NDErs' manner of living from changes in attitude and belief.

In sum, Schroeter-Kunhardt's letter contains a number of assertions that are not only wrong, but belie what we have written. Let me conclude with a personal comment: When starting our work (which was finished more than three years ago), we had hoped to initiate a real scientific discussion on NDEs in the German speaking countries across disciplines. Our edited volume (Knoblauch and Soeffner, 1999) was one of the fruits of this hope. As Schroeter-Kunhardt's untenable assertions show, the discussion has still to be developed in a more serious and unbiased fashion.

\section{References}

Knoblauch. H. (1999). Berichte aus dem Jenseits. Freiburg, Germany: Herder.

Knoblauch, H., Schmied, I., and Schnettler, B. (2001). Different kinds of near-death experience: A report of a survey of near-death experiences in Germany. Journal of Near-Death Studies, 20, 15-19.

Knoblauch, H., and Soeffner, H.-G. (Eds.). (1999). Todesnähe: Interdisziplinäre Zugänge zu einem aussergewöhnlichen Phänomen. Konstanz, Germany: Universitätsverlag Konstanz.

Dr. Hubert Knoblauch

Theologisches Seminar

Kirchgasse 9

CH 8001 Zürich 